\title{
Reflexões analíticas sobre uma região metropolitana do sul do Brasil: a região de Chapecó/SC
}

\author{
Claudio Maia ${ }^{1}$ \\ Osmar Tomaz de Souza²
}

Submissão: $26 / 06 / 2021$

Aceite: $18 / 09 / 2021$

\begin{abstract}
Resumo
Esta reflexão teórica metodológica comparativa da região metropolitana de Chapecó/SC (RMChap), a partir da análise de dados secundários e respectiva concepção de hipóteses explicativas, busca produzir sínteses propositivas que apontam caminhos para compreender a racionalidade e dinamismo regional no âmbito da região metropolitana e sua área de influência. A partir da análise dos macrossetores produtivos, indicação das potencialidades regionais das distintas regiões econômicas, busca-se o fomento das atividades e das potencialidades regionais nas quais cada região se mostra mais competitiva. Uma vez definidos os segmentos nos quais cada região é mais competitiva, é possível levar à frente uma política coordenada entre os diversos atores e modelos organizacionais. 0 principal indicador das potencialidades de desenvolvimento regional é sua especialização atual, aproximando a ideia de "potencial", num esforço de identificação do grau de especialização e concentração das atividades produtivas. A estratégia metodológica privilegiou, num primeiro momento, análise de aspectos, dados econômicos e populacionais com dados estatísticos secundários, buscando-se definir um diagnóstico preliminar das potencialidades regionais; no segundo momento, a partir do levantamento de dados e informações, testou-se a consistência e a economicidade das hipóteses sugeridas no diagnóstico preliminar. Identificou-se potencialidades no setor industrial e serviço na RMChap, setores que vêm ganhando espaço na economia regional nas últimas décadas. Identificou-se setores que apresentam maior potencial, baseado no estudo dos QLs e do VAB. Dada a expansão da ocupação populacional, das atividades econômicas e intensa urbanização, há forte tendência a expansão do setor de serviço decorrente das aglomerações urbanas e urbanização das áreas rurais.
\end{abstract}

Palavras-chave: Análise regional. Especialização produtiva. Desenvolvimento regional.

\section{Analytical reflections on a metropolitan region in southern Brazil: the region of Chapecó/sC}

\begin{abstract}
This comparative theoretical methodological reflection of the metropolitan region of Chapecó/SC (RMChap), based on the analysis of secondary data and the respective conception of explanatory hypotheses, seeks to produce propositional syntheses that point out ways to understand regional rationality and dynamism within the scope of metropolitan region and its area of influence. From the analysis of the productive macro-sectors, the indication of the regional potentialities of the different economic regions, we seek to foster the activities and regional potentialities in which each region is more competitive. It is understood that, once the segments in which each region is more competitive are defined, it is possible to carry out a coordinated policy between the various actors and organizational models. The main indicator of the potential of regional development is its current specialization, approaching the idea of "potential", in an effort to identify the degree of specialization and concentration of productive activities. The methodological strategy favored, at first, analysis of economic and population aspects and data with secondary statistical data, seeking to define a preliminary diagnosis of regional potentialities; in the second moment, from the data and information survey, the consistency and economy of the hypotheses suggested in the preliminary diagnosis were tested. Potentials were identified in the industrial and service sectors at RMChap, sectors that have been gaining ground in the regional economy in recent decades. The sectors with the greatest potential were identified, based on the study of QLs and GVA. Given the expansion of population occupation, economic activities and intense urbanization, there is a strong tendency for the service sector to expand due to urban agglomerations and urbanization of rural areas.
\end{abstract}

\footnotetext{
${ }_{1}^{1}$ Pós-Doutorado em Economia do Desenvolvimento (PUC/RS). Professor do Programa em Desenvolvimento Regional da Universidade do Contestado (UnC). https://orcid.org/0000-0002-5144-9153. Email:claudiomaia.dr@hotmail.com

${ }^{2}$ Pós-Doutorado em Economia Agrária (Université Paris-Ouest Nanterre la Défense). Professor do Programa de Pós-Graduação em Economia do Desenvolvimento da Pontifícia Universidade Católica do Rio Grande do Sul (PUC/RS). Email: osmar.souza@pucrs.br
} 
Keywords: Regional analysis. Productive specialization. Regional development.

\section{Introdução}

No Brasil, são poucas as pesquisas e os estudos que tratam da região metropolitana no contexto desenvolvimento regional. Considerando essa realidade, esse artigo discute sobre potencial ou dinâmicas da economia política do desenvolvimento regional, ao identificar e descrever potencialidade regional numa perspectiva comparativa do processo de desenvolvimento regional. Para dar conta do proposto, duas estratégias centrais de produção foram desenvolvidas: a produção e organização teórica metodológica comparativa da região metropolitana de Chapecó/SC, a partir da análise de dados secundários e a respectiva concepção de hipóteses explicativas, produzindo sínteses propositivas e diagnostico preliminar apontando possíveis caminhos para compreender a racionalidade e o dinamismo regional; e, revisão e racionalidade bibliográfica utilizada no estudo e análises realizadas.

A dinâmica de desenvolvimento regional acontece de várias perspectivas. Conforme aponta Becker (2002), Maia (2019a), Maia e Pitschel (2019a, 2019b), observa-se uma renovada importância do local e uma tendência para estimular culturas regionais. Fica-se surpreso quando alguns autores afirmam que é em função de seu histórico de valores culturais acumulados regionalmente, ou do "capital social" existente, que algumas regiões conseguem responder positiva e ativamente aos desafios regionais da globalização contemporânea construindo seus próprios modelos de desenvolvimento, ao conseguirem desenvolver suas potencialidades e aproveitar as oportunidades decorrentes da dinâmica global de desenvolvimento, combinando eficientemente o desenvolvimento de suas potencialidades com as oportunidades globais, constituindo uma dinâmica própria regional.

Portanto, hipoteticamente, “as diferentes dinâmicas de desenvolvimento regional dependem de uma crescente organização social das comunidades regionais. $E$ uma crescente organização social equivale diretamente a um melhor envolvimento político nas decisões e definições dos rumos do desenvolvimento regional. Da mesma forma, uma melhor participação política leva, consequentemente, a um maior desenvolvimento econômico das comunidades regionais" (BECKER, 2002, p.40; MAIA, 2019a, 2019b).

Para Boisier (1996) o desenvolvimento de uma região em longo prazo depende de fatores determinantes, tais como, os critérios econômicos e políticos que permitem, ou não, a participação de recursos nacionais na região, a capacidade de organização social e econômica, 
capaz de impulsionar potencialidades de crescimento, adotando para si um caráter independente e fortalecendo sua identidade, sem desconsiderar o impacto que as políticas econômicas nacionais têm sobre a região. A partir disso o território deve ser entendido de forma multidisciplinar, a fim de compreender o que o envolve em seu todo, seja através das ciências políticas e sociais, da economia, da história e da geografia.

A abordagem do termo "região" pode ser entendida de diversas maneiras. De forma generalista, região pode ser conceituada como a área que em sua proximidade geográfica se identifique determinada característica própria, que pode ser gerada por uma atividade econômica, geográfica ou até mesmo a necessidade de classificar uma área para delimitar um objeto de estudo. Desta forma, indica-se que o termo região pode ser impreciso, já que a regionalização de uma área varia conforme os critérios adotados. No entanto, para Paiva (2005), região é como o resultado de um processo de regionalização. Processo em função dos objetivos daqueles que o colocam em curso.

Para tanto assume-se o conceito de território, defendido por Souza (2000), como sendo o espaço entendido e estabelecido a partir das relações e do exercício de poder, sendo este a capacidade humana de agir em conjunto e em comum acordo e por isso necessitando de legitimidade.

\footnotetext{
Os estudos mais recentes sobre território como uma criação coletiva e institucional, indicam, por um lado, que a formação de um território resulta do encontro e da mobilização dos atores sociais que integram um dado espaço geográfico e que procuram identificar e resolver problemas comuns. Por outro lado, demonstram que um "território dado", cuja delimitação é político-administrativa, pode abrigar vários "territórios construídos". E sua construção pressupõe existência de uma relação de proximidade dos atores (MAIA, 2014, p.128; PECQUEUR, 1996 apud VIEIRA e CAZELLA, 2008, p.6).
}

A abordagem territorial exige a análise das instituições em torno das quais se organiza a interação social localizada, considerando os custos de transação sob um ângulo histórico e a partir da influência que sobre eles exercem as forças sociais que os constituem (NORTH, 2018, 1994a; 1994b, p.360; 1991, p.97-98). Nesta perspectiva, o estudo empírico dos atores e de suas organizações torna-se importante para a compreensão de situações localizadas. Vis-à-vis a esta perspectiva, a abordagem territorial do desenvolvimento estimula o estudo dos mecanismos de governança pública subjacentes à composição e à atuação dos conselhos de desenvolvimento, em torno da questão de que "seriam capazes de oferecer oportunidades de inovação organizacional que estimule o empreendedorismo privado, público e associativo em suas respectivas regiões" (ABRAMOVAY, 2007, p.20-21). 
A partir destas considerações teóricas metodológicas, este estudo apresenta reflexões que investigam dinâmicas regionais, no âmbito do contexto da região metropolitana. Tal como a necessidade de indicação das potencialidades regionais das distintas regiões econômicas, da região metropolitana de Chapecó/SC (RMChap), visando-se ao fomento das atividades e das potencialidades regionais nas quais cada região se mostra mais competitiva. Entendendo-se que, uma vez definidos os segmentos nos quais cada região é mais competitiva, é possível levar à frente uma política coordenada entre os diversos atores e modelos organizacionais.

Conforme Riedl, Maia e Schuster (2008), Maia (2016), Pinto e Meza (2020), há vários trabalhos que estão sendo realizados sobre a preocupação com as desigualdades regionais, bem como a identificação das potencialidades ou gargalos ao desenvolvimento regional (PAIVA, 2004, 2005, 2006; COSTA, DENTINHO e PETER, 2011; PIACENTI, LIMA E EBERHARDT, 2016). E, tal é a preocupação com a ocupação dos espaços nos processos de desenvolvimento, que o êxito dos estudos em economia regional está sujeito ao conhecimento das particularidades e dos potenciais das regiões objeto de investigação. "O processo de desenvolvimento regional deixa de ser pura e simplesmente uma questão quantitativa e adquire crescentes dimensões qualitativas, através do pleno reconhecimento e do pleno desabrochar das diversidades regionais", o que nos remete à necessidade de se medir e considerar, perfis e produtividades espaciais diferentes segundo os lugares diferentes, e chegar-se a processos de desenvolvimento diferentes (BECKER, 2002, p.88).

Conforme Paiva (2006a), Maia e Pitschel (2019a, 2019b), o principal indicador das potencialidades de desenvolvimento endógeno de uma região é a sua especialização atual, aproximando a ideia de "potencial", baseando-se nas alternativas existentes para a região, suas possibilidades futuras e suas chances de superação, da ideia de "especialização" a qual trata de trajetórias já trilhadas, de opções já feitas. Sendo assim, possuir um adequado diagnóstico das especificidades das dinâmicas produtivas é indispensável para fundamentar projetos e políticas de desenvolvimento local/regional. Tal fato é justificado, assim, pelo esforço de identificação do grau de especialização e concentração das atividades produtivas, para qualificar as aglomerações geográficas e setoriais que podem ser potencializadas por ações conjuntas, ou no sentido de incrementar a cooperação entre as unidades produtivas, ou no direcionamento das políticas públicas.

Parte da inspiração deste estudo é devido a um caminho teórico metodológico empírico onde depara-se com um conjunto de autores que embora há muito tempo sejam referência teórica, aqui são lidos como teóricos do desenvolvimento regional. Adotou-se a contribuição de 
Paiva $(2004)^{1}$, onde indica-se que há muito terreno a percorrer até se obter um programa de identificação das potencialidades econômicas regionais que nos contemple plenamente. Outra inspiração, surge a partir da experiência realizada nas Conferências Estaduais e Nacional de Desenvolvimento Regional ${ }^{2}$. Também, destacam-se vários trabalhos sobre temáticas das desigualdades regionais que tem sido realizados (MACEDO e MONASTERIO, 2016; PAIVA, 2013 e 2004; COSTA, DENTINHO e PETER, 2011; COSTA e NIJKAMP, 2009; DINIZ e CROCCO, 2006; BECKER, 2002; DINIZ, 2000; BENKO, 1999; NORTH, 1959, 1955) e, tal é a preocupação com a ocupação dos espaços nos processos de desenvolvimento, que o êxito dos estudos em economia regional está sujeito ao conhecimento das particularidades e dos potenciais das regiões objeto de investigação.

\section{Estratégia metodológica}

Se o ponto de chegada de uma pesquisa sobre as potencialidades regionais deve envolver a identificação dos territórios submetidos a um mesmo padrão de dinâmica econômica, o ponto de partida só pode ser a subdivisão territorial consolidada nas práticas políticas cotidianas, o que em Santa Catarina vale dizer que, tanto poderia ser tomadas as associações de municípios como regiões econômicas no sentido da definição de Hoover e Fischer, Costa e Nijkamp, assim como, a área de influência de Chapecó e de outras cidades influentes. E, isto porque a hipótese simplificadora nos permite ir diretamente ao tema que organiza este estudo, a noção para definição dos indicadores que devem ser construídos (dada a grande disponibilidade de dados secundários) com vistas a garantir a máxima consistência e determinação ao diagnóstico preliminar de potencialidades regionais. Sendo assim, a delimitação deste estudo envolve, objetivamente, a região metropolitana de Chapecó/SC e seus respectivos municípios pertencentes. A estratégia metodológica baseou-se na aplicação em exercícios anteriores e em resultados de pesquisas apresentados em estudos anteriores (MAIA e ROLIM, 2015; VILLELA, ALBA, MAIA e ARRUDA, 2015; MAIA, SANTIN, ALBA e VILLELA, 2014; MAIA, FUJITA, ALBA, 2013; FUJITA, MATIELLO e ALBA, 2009) e no documento do IBGE (2007), acerca da região de influência

\footnotetext{
${ }^{1}$ Em seu trabalho intitulado "Como se Identifica o Potencial de uma Região?".

${ }^{2}$ Da tentativa de formular uma política regional de uma maneira diferente, de suas metas, objetivos, instrumentos e medidas.
} 
das cidades, onde privilegiou a análise de aspectos e dados econômicos e populacionais, a partir de fontes primárias e secundárias, além de trabalhos de campo.

Num primeiro momento da pesquisa realizada para a produção deste estudo, trabalhouse com dados estatísticos secundários, buscando-se definir um diagnóstico preliminar das potencialidades regionais. No segundo momento, buscou-se levantamento de dados e informações, buscando-se testar a consistência e a economicidade das hipóteses sugeridas no diagnóstico preliminar.

\section{Pressuposto da análise regional}

Considerando-se a heterogeneidade das regiões metropolitanas, na região metropolitana de Chapecó/SC, defronta-se com um dos principais problemas das análises regionais. As regionalizações não partem de regiões objetivamente determinadas, e sim de regiões tradicionais, ou regiões político-administrativas. Conforme Boudeville (in PAIVA, 2006c, p.4), o problema era que os dados regionais se agrupam por unidades administrativas e esses agrupamentos políticos não coincidem com as diferenciações nem com as organizações econômicas, nem mesmo com uma região polarizada. De acordo com Breitbach (1988, p.39), este tipo de região polarizada "expressa-se num meio urbano em que as atividades industrial e comercial preponderem e irradiam fluxos de trocas de bens e serviços com o campo e cidades satélites [...] sob a influência do polo".

As regionalizações político-administrativas proporcionam três vantagens para a investigação e a coleta de dados: (1) permite que se opere com bases de dados tal como elas são usualmente disponibilizadas (a partir de limites territoriais definidos no plano políticoadministrativo); (2) é solidário com o senso comum consolidado e os interesses imediatos de gestores públicos das distintas instâncias administrativas; e (3) poupa o pesquisador do trabalho de re-regionalizar. Entretanto, essa facilidade de opção induz conclusões erradas. Primeiro, porque sempre há heterogeneidades nas sub-regiões reais que compõem uma macrorregião. Segundo tais heterogeneidades são decorrentes das divisões do território que não obedecem a nenhum critério lógico e/ou metodológico, por isso simplesmente aceitam divisões políticoadministrativas.

Quanto aos limites territoriais definidos no plano político-administrativo, não se defende o ponto de vista de que se deveria ignorar o padrão no qual são disponibilizadas as bases de dados. Diz-se, sim, é que não há por que subordinar-se às mesmas: agregar (e, por vezes, até 
cindir) é possível e, inúmeras vezes, necessário. E esta agregação (ou cisão) não tem que se submeter aos padrões tradicionais, mas pode e deve ser definida pelo pesquisador. Quanto às divisões político-administrativas, numa perspectiva geográfica específica, alguns autores diriam que não se está falando do conceito de região e, sim, de território. Território, dizendo respeito a um espaço definido por relações de poder que, neste caso, teria por base a dimensão jurídicopolítica (relações espaço-poder institucionalizadas) (HAESBAERT; SOUZA in PAIVA, 2006, p.7).

\section{Pressupostos da medida de especialização: o Quociente Locacional (QL)}

O ponto de partida da pesquisa é impositivo, e como condição sine qua non para a definição das características da pesquisa primária. Pois, não se pode definir sequer o modelo de levantamento primário de informações (tipo e padrão de seleção da amostra, instrumento de coleta de dados, recursos humanos, materiais e temporais necessários à realização do levantamento e a sistematização dos dados coletados), sem que se responda, à luz dos dados secundários, algumas questões cruciais. Estas questões a serem respondidas são: qual(is) é(são) a(s) nossa(s) principal(is) suspeita(s) de potencial(is)? ; qual(is) o(s) nosso(s) principal(is) suspeito(s) de gargalo(s)? ; no caso de haver diversos suspeitos de potencial e gargalo, é possível hierarquizá-los? ; e, o que fica mal explicado na análise dos dados secundários? Além destas, ainda têm que ser respondidas: onde aparecem os resultados inesperados, problemas e contradições? e que trabalho de pesquisa seria necessário para o adequado enfrentamento desses problemas e contradições? (PAIVA, 2004, p.13). E, para responder a esse conjunto de questões, de forma determinada, analisou-se a região-objeto a partir de recortes cada vez mais restritivos e específicos (no sentido macrorregião, região, microrregião e município). Assim, então, foram comparadas as medidas pertinentes a cada um desses recortes com as medidas equivalentes para regiões de referência definidas em patamares superiores de agregação (no sentido nação, macrorregião e região microrregião). A forma para fazer isto foi utilizando uma racionalidade analítico interpretativa que remete a uma medida clara da especialização produtiva regional, nomeadamente, o que nesta pesquisa será adotada na racionalidade da noção de Quociente Locacional (QL). Para delimitar especializações dentro da região e apontar

algumas das características da estrutura produtiva local e identificar padrões regionais de crescimento econômico, utiliza-se, com certa frequência, um conjunto de medidas de localização e especialização como métodos de análise regional, onde a mais difundida das medidas de especialização regional na literatura econômica, é o Quociente Locacional (QL) (HADDAD, 1989; 
MONASTERIO, 2011; DELGADO E GODINHO, 2011). Segundo Paiva (2004), a medida de participação (neste caso a especialização relativa) mais utilizada é a percentagem dos empregos gerados no setor/segmento vis-à-vis ao conjunto dos empregos do território. Para isto adota-se:

$$
\mathrm{QL}=\frac{\frac{\text { Número de trabalhadores do setor } \mathrm{Y} \text { na região } \mathrm{x}}{\text { Número de trabalhadores da região } \mathrm{x}}}{\frac{\text { Número de trabalhadores do setor } \mathrm{Y} \text { na região } \mathrm{z}}{\text { Número de trabalhadores da região } \mathrm{z}}}
$$

Onde, a região X representa a microrregião (município, região), da qual se busca a participação relativa em função da região $Z$ que representa a macrorregião (estado, nação).

A racionalidade de utilização do QL para análise regional, é desenvolvida neste estudo para a caracterização da área de influência de Chapecó/SC, apresentando uma caracterização baseada na investigação dos QLs dos macrossetores agropecuário, industrial e serviços, bem como dos municípios que compõem a referida região, com vistas a identificar o nível de especialização dos respectivos setores e/ou produtos e serviços existentes na região. Por outro lado, também serão utilizadas outras técnicas analíticas, o que aumenta a capacidade de se compreender os problemas que estão sendo investigados (HADDAD, 1989; MONASTERIO, 2011; DELGADO E GODINHO, 2011). Conforme Paiva (2006b), o quociente de localização informa não apenas se o objeto de mensuração é ou não especializado (e o quanto é especializado), mas também, na medida em que o objeto não apresenta especialização. Neste trabalho, optou-se por um pseudo-QL, obtido a partir do cruzamento das informações disponíveis. Neste caso o VAB Total e o VAB dos macrossetores agropecuário, indústria e serviços, para cada segmento em análise (município e região de pesquisa), relativamente á região de referência (região, estado). De forma que o Quociente Locacional (QL) para o macrossetor agropecuária toma a seguinte forma:

$$
\mathrm{QL}=\frac{\frac{\mathrm{VAB} \text { da agropecuária no município }}{\text { VAB total do município }}}{\frac{\text { VAB da agropecuária na região } S C}{\text { VAB total na região SC }}}
$$

Dado a característica de especialização relativa sinalizado pelo Quociente Locacional, adota-se para fins práticos: QL $\leq 1$ como indicador de setores (macrossetores em nossa pesquisa) que não possuem especialização relativa; e QL > 1 como indicador de especialização relativa, sendo que quanto maior o QL, maior a especialização relativa do setor. 


\section{A região metropolitana de Chapecó/SC}

A Lei Complementar no 104, de 04 de janeiro de 1994 dispõe sobre os princípios da regionalização do Estado de Santa Catarina a fim de desenvolver ação administrativa regionalizada, definir as funções públicas de interesse regional e assegurar sua gestão.

A Região Metropolitana de Chapecó (RMChap) foi instituída pela Lei Complementar № 377, de 17 de abril de 2007, sendo uma das dez regiões criadas pelo estado de Santa Catarina e a 41a em população das 63 Regiões Metropolitanas Brasileiras. Estrutura-se a partir de um núcleo composto por 16 municípios e uma área de expansão, previamente definida, composta por nove municípios (Figura 1).

Figura 1 - Região metropolitana de Chapecó e sua respectiva área de expansão ${ }^{3}$

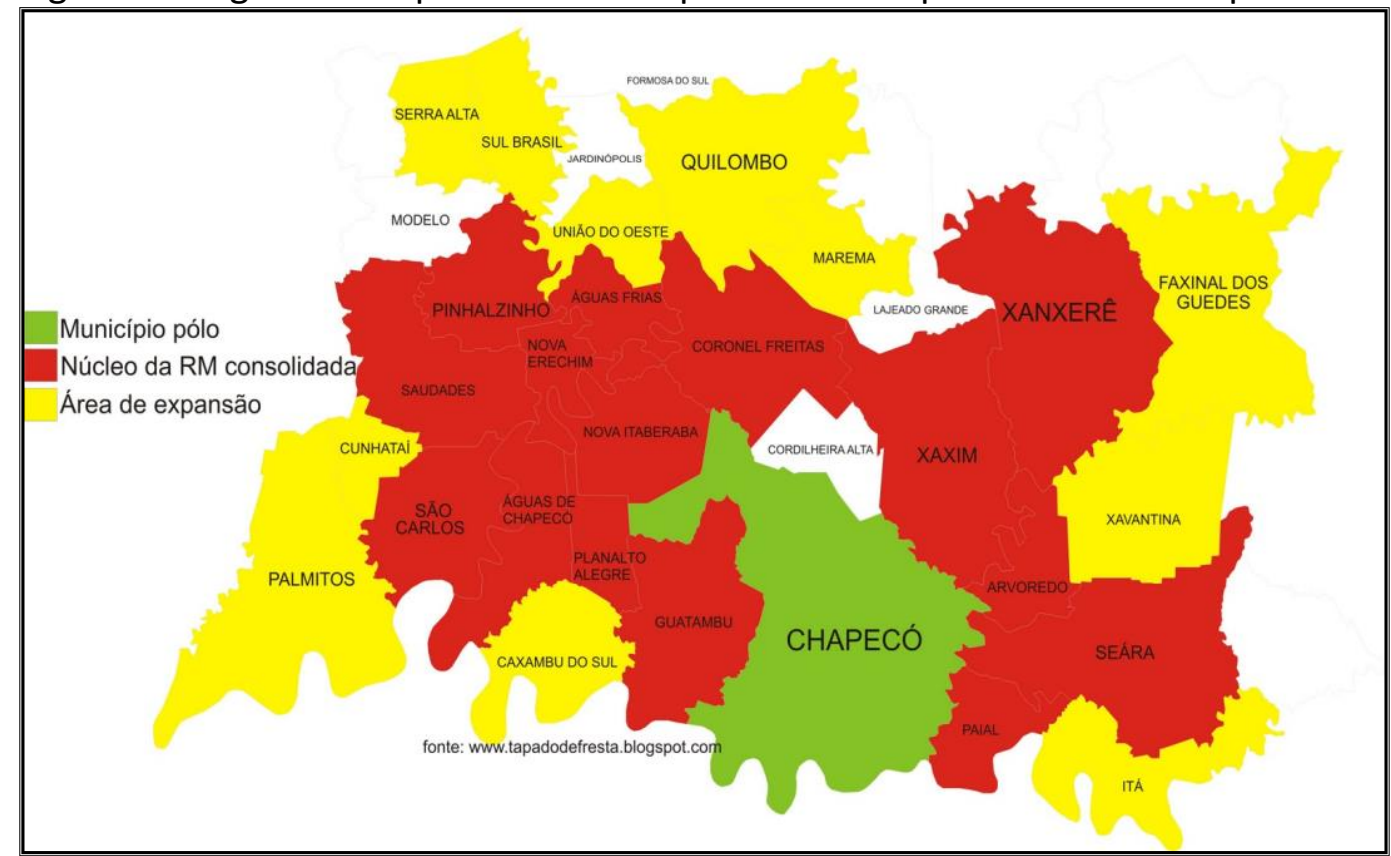

Fonte: Lei Complementar № 377, de 17 de abril de 2007

$\mathrm{Na}$ figura 2 tem-se o confrontamento das informações contendo Associações de Municípios, Secretarias de Desenvolvimento Regional (SDRs) e Região Metropolitana de Chapecó.

\footnotetext{
${ }^{3}$ Reúne 16 municípios do estado de Santa Catarina em processo de conurbação, além de outros 9 municípios que compunham a denominada área de expansão metropolitana, totalizando 25 municípios. O núcleo metropolitano é composto pelos municípios de Chapecó, Xanxerê, Xaxim, Arvoredo, Paial, Seara, Guatambu, Planalto Alegre, Nova Itaberaba, Coronel Freitas, Pinhalzinho, Águas Frias, Nova Erechim, Águas de Chapecó, Saudades e São Carlos. A área de expansão metropolitana conta com os municípios de Itá, Xavantina, Faxinal dos Guedes, Marema, Quilombo, União do Oeste, Caxambu do Sul, Palmitos e Cunhataí.
} 
Figura 2 - Compreensão da Região Metropolitana de Chapecó conjuntamente com as Associações de Municípios e SDRs

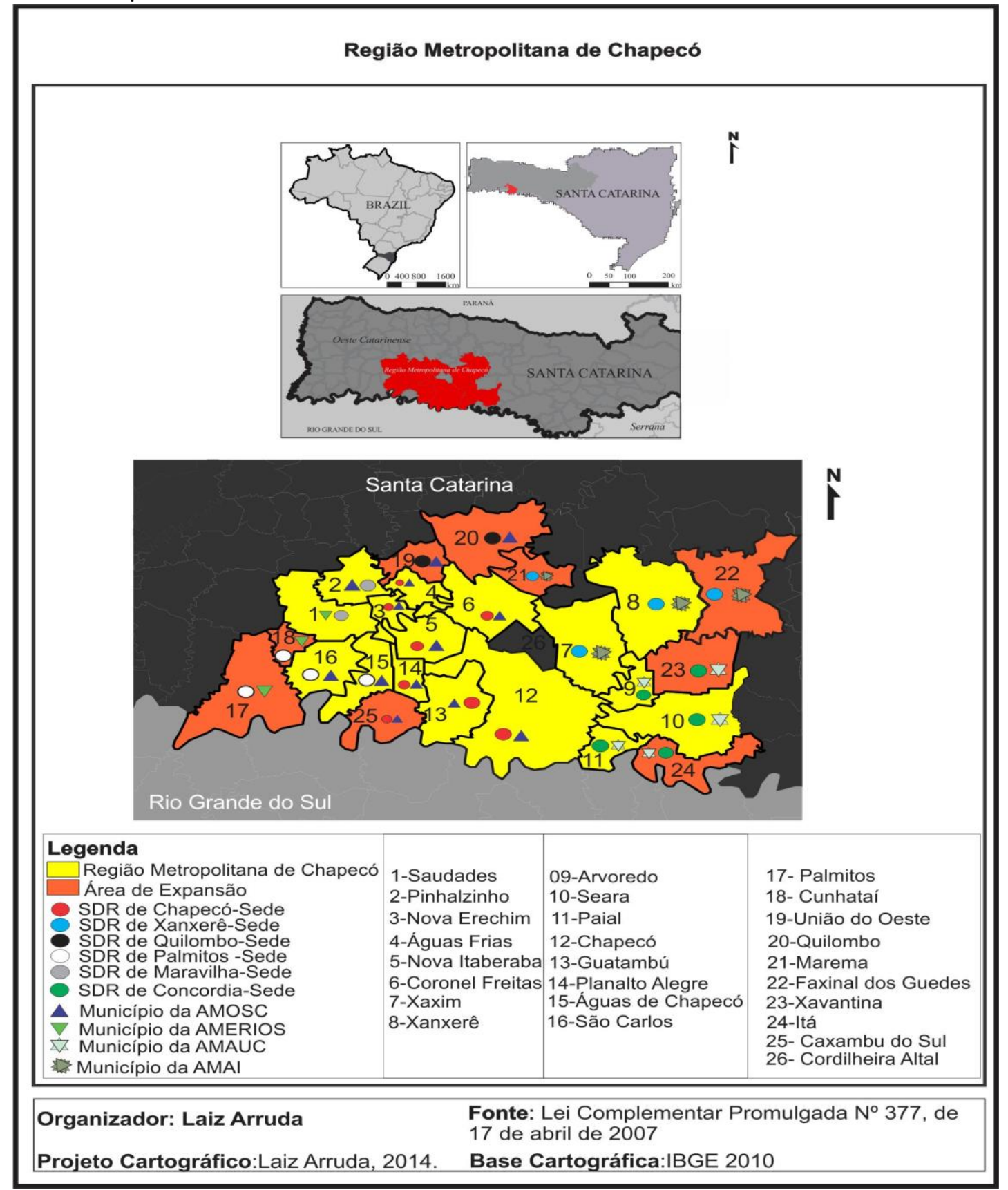

Teoricamente, expansão pode ser definida como a ação de estender-se, difundir ou espalhar. Contrariando este entendimento a Lei da Região Metropolitana de Chapecó dispõe que ela será composta por um Núcleo Metropolitano e uma Área de Expansão Metropolitana, tendo como sede o Município de Chapecó, adotando como critério para os municípios da área de expansão os que: I. apresentem dependência de utilização de equipamentos públicos e serviços 
especializados do Núcleo Metropolitano, com implicação no desenvolvimento da região; e II. apresentem perspectiva de desenvolvimento integrado, através da complementaridade de funções.

Interessante observar que esta Lei desde a sua origem, antevendo sua importância na dinâmica econômica regional, pontua uma área de expansão. A Lei delimita, portanto, uma suposição de como pode caminhar a economia e o desenvolvimento regional ao delimitar previamente quais municípios farão parte da expansão e ignora o possível crescimento de outras cidades limítrofes, tal como Cordilheira Alta que se apresenta como exceção isolada neste contexto metropolitano.

Pode-se visualizar o descompasso entre estas organizações no que tange o atendimento aos municípios e consequentemente fragilizando o desenvolvimento regional, bem como a incógnita da lacuna deixada pelo Município de Cordilheira Alta, ao não ser incorporado à Região Metropolitana de Chapecó e nem à sua expansão (MAIA et. al, 2019b; VILLELA et. al, 2015).

\section{Apresentação e análise dos resultados}

A estrutura produtiva da região de pesquisa (aqui denominada Região Metropolitana de Chapecó), comparativamente com o total estadual, possui predomínio no setor agropecuário, o qual é responsável por $12,59 \%$ do VAB (Valor Adicionado Bruto) da agropecuária no estado de Santa Catarina no ano de $2017^{4}$ (Gráfico 1). Os setores indústria e serviços contribuíram, respectivamente, com $12,24 \%$ e $10,82 \%$, na estrutura do VAB no estado. No mesmo ano a região de pesquisa foi responsável por $11,38 \%$ do VAB total do estado de Santa Catarina (Gráfico 2).

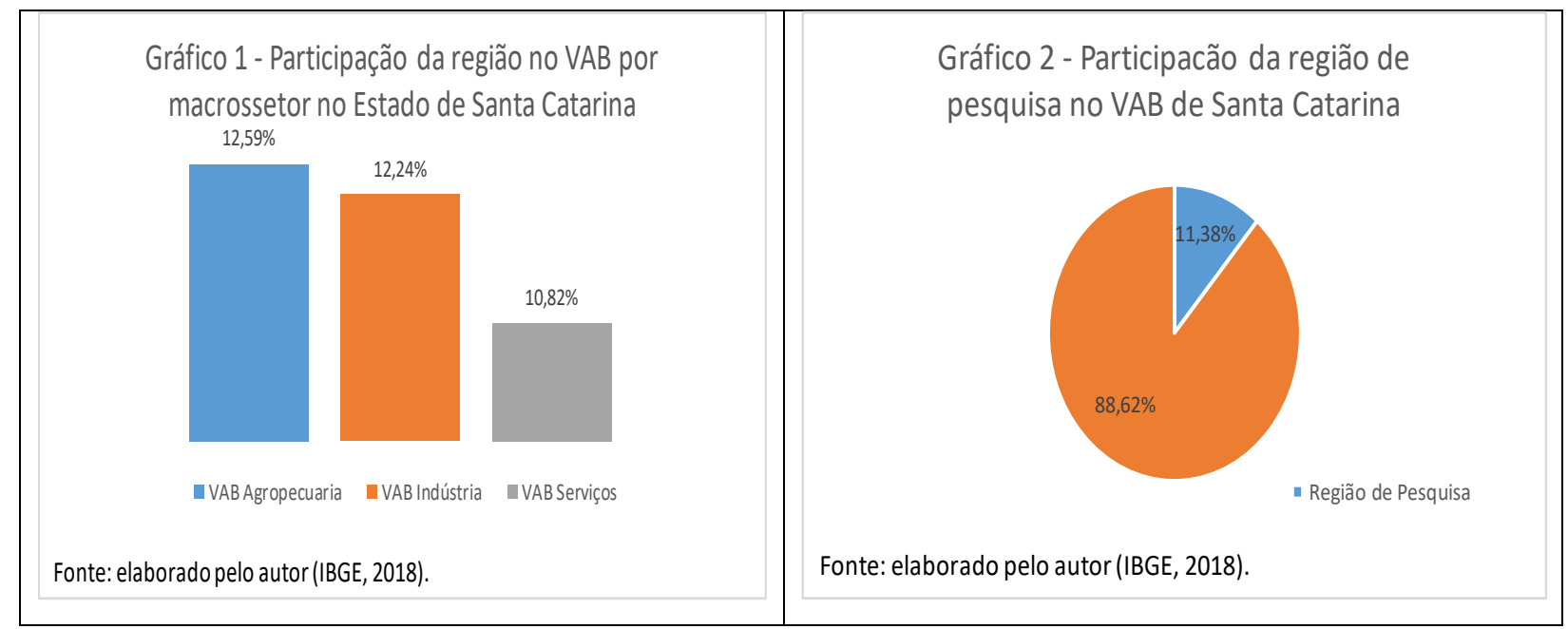

${ }^{4}$ O IBGE possui dados atualizados do VAB, somente até o ano de 2017. 
Observa-se no gráfico 3, que a estrutura produtiva da Região Metropolitana de Chapecó, comparativamente aos municípios que a compõe apresenta predomínio no setor de serviços, sendo este responsável por 57,10\% do VAB total da região em 2010 e 59,29\% em 2018. Em seguida observa-se uma expressiva participação da indústria representando em 2010 e 2018, respectivamente, $32,83 \%$ e $33,59 \%$ do VAB total da região de pesquisa. O setor agropecuário foi o que apresentou menor participação relativa no VAB total da região, apresentando uma participação relativa de 10,07\% e 7,12\%, respectivamente, para 2010 e 2018 - a participação relativa do setor agropecuário apresentou redução de 29,33\% do ano de 2010 para 2018.

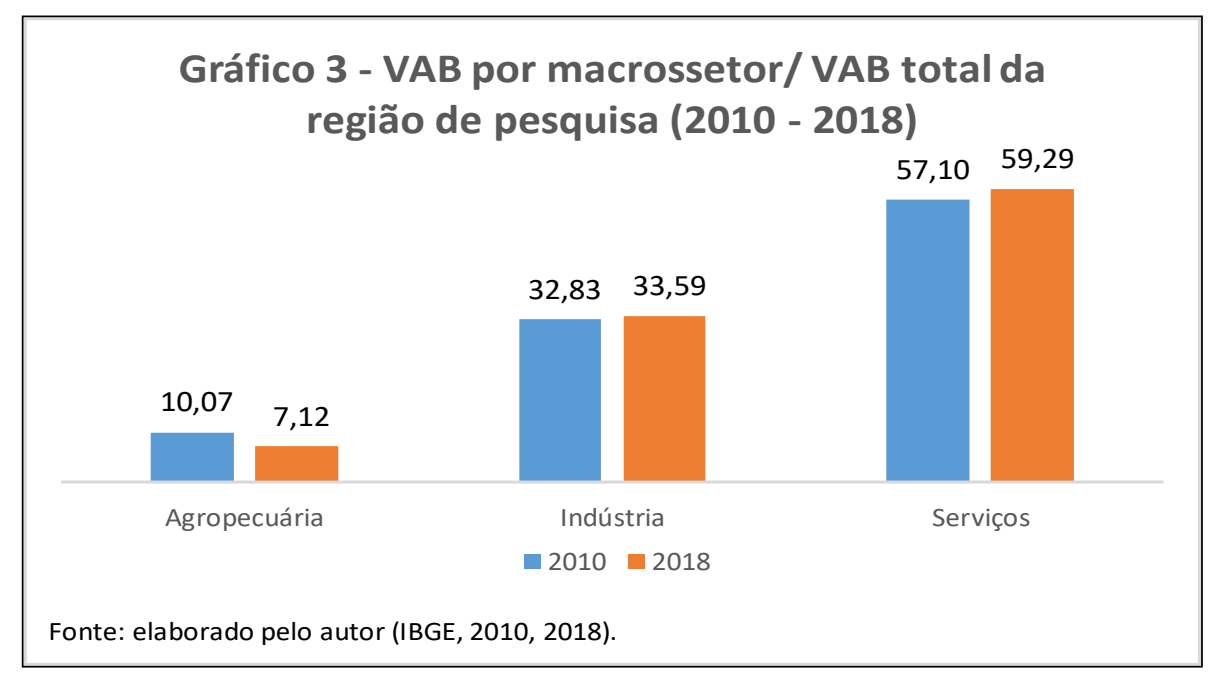

A análise da composição relativa do VAB entre os municípios, revela uma participação expressiva de Chapecó (aqui considerado como pólo regional), município responsável por 30,33 \% da composição do VAB total da região (Gráfico 4), o que é trivial uma vez que Chapecó agrega 30,23 \% da população total da região (Gráfico 5). 


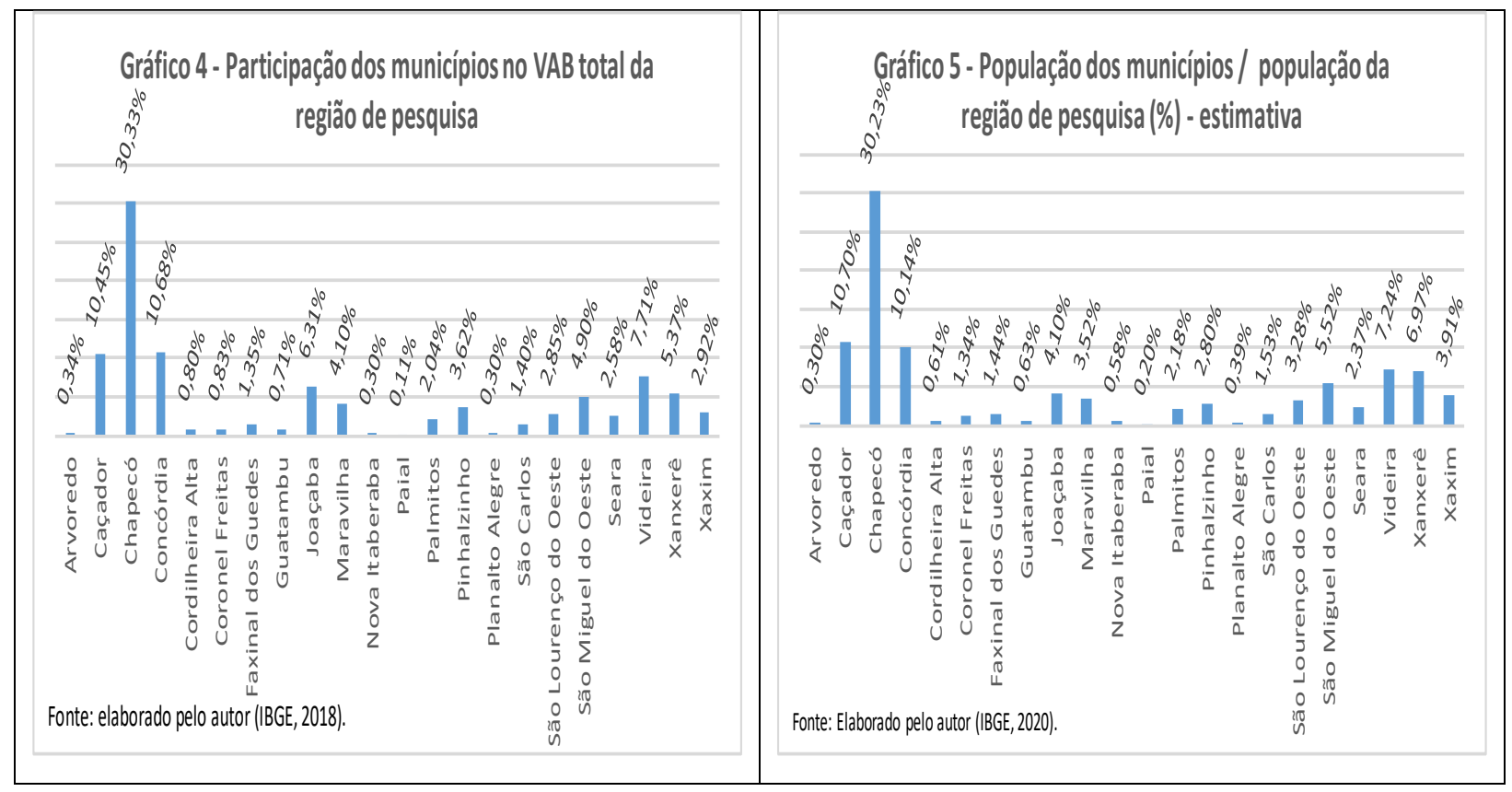

Nos gráficos 6 e 7, pode-se observar de maneira intuitiva a dinâmica entre os macrossetores produtivos (agropecuária, indústria e serviços), que revelam o predomínio do setor de serviços nos municípios no ano de 2010, representando quase sempre mais que $42 \%$ do VAB total (47,94\% do VAB total, em média), chegando a representar 66,51\% em Chapecó, 63,16\% em São Miguel do Oeste e 69,25\% em Joaçaba.

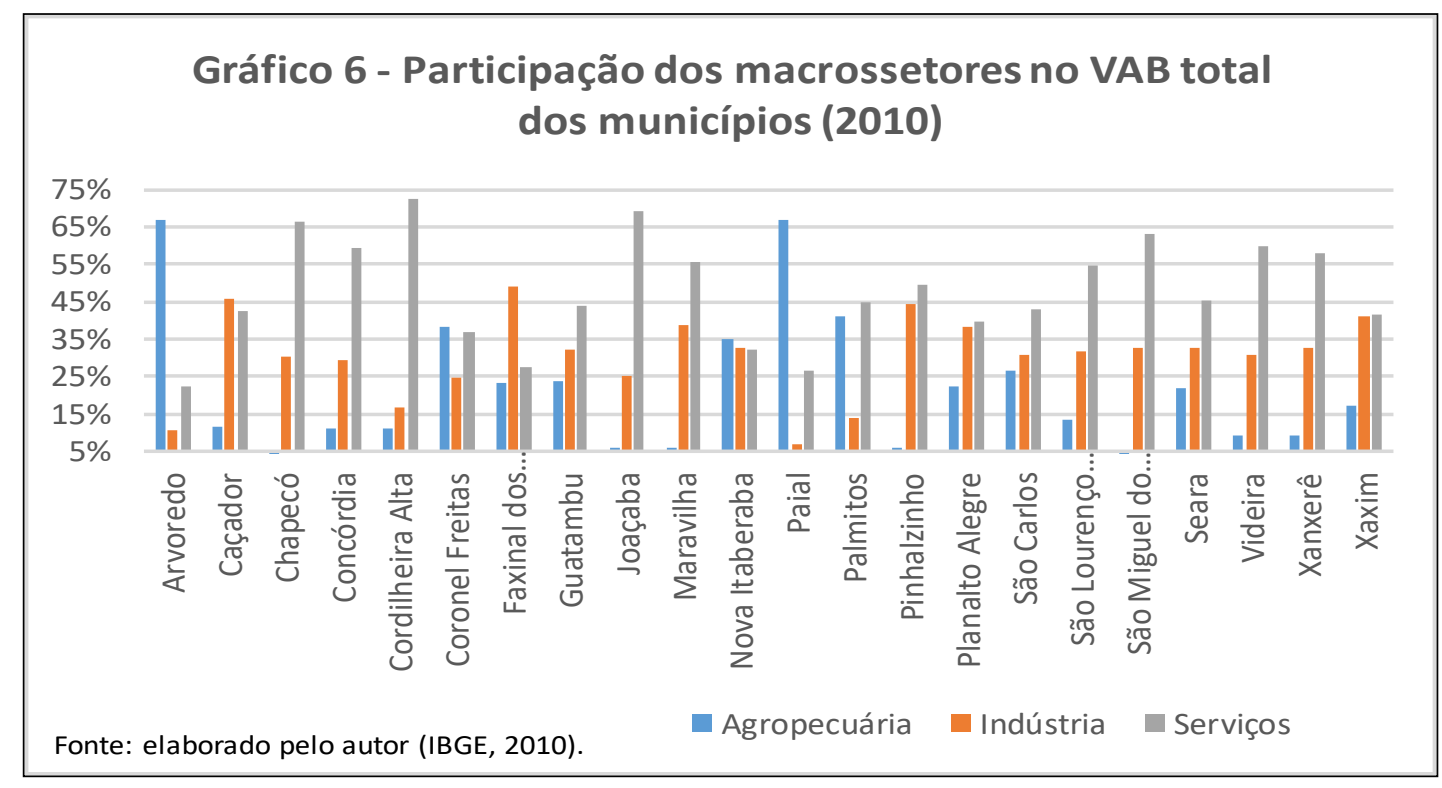

Em 2018, o predomínio do setor serviços, se mantém para 18 dos 22 municípios analisados, com exceção de Guatambu, cujo predomínio passou a ser a indústria com VAB de 44,41\% (em 2010, possuía 43,77\% do VAB em serviço); e Planalto Alegre, que passou a ter $63,12 \%$ do VAB da agropecuária (em 2010 possuía 39,49\% do VAB no setor de serviços) (Gráfico 7). 


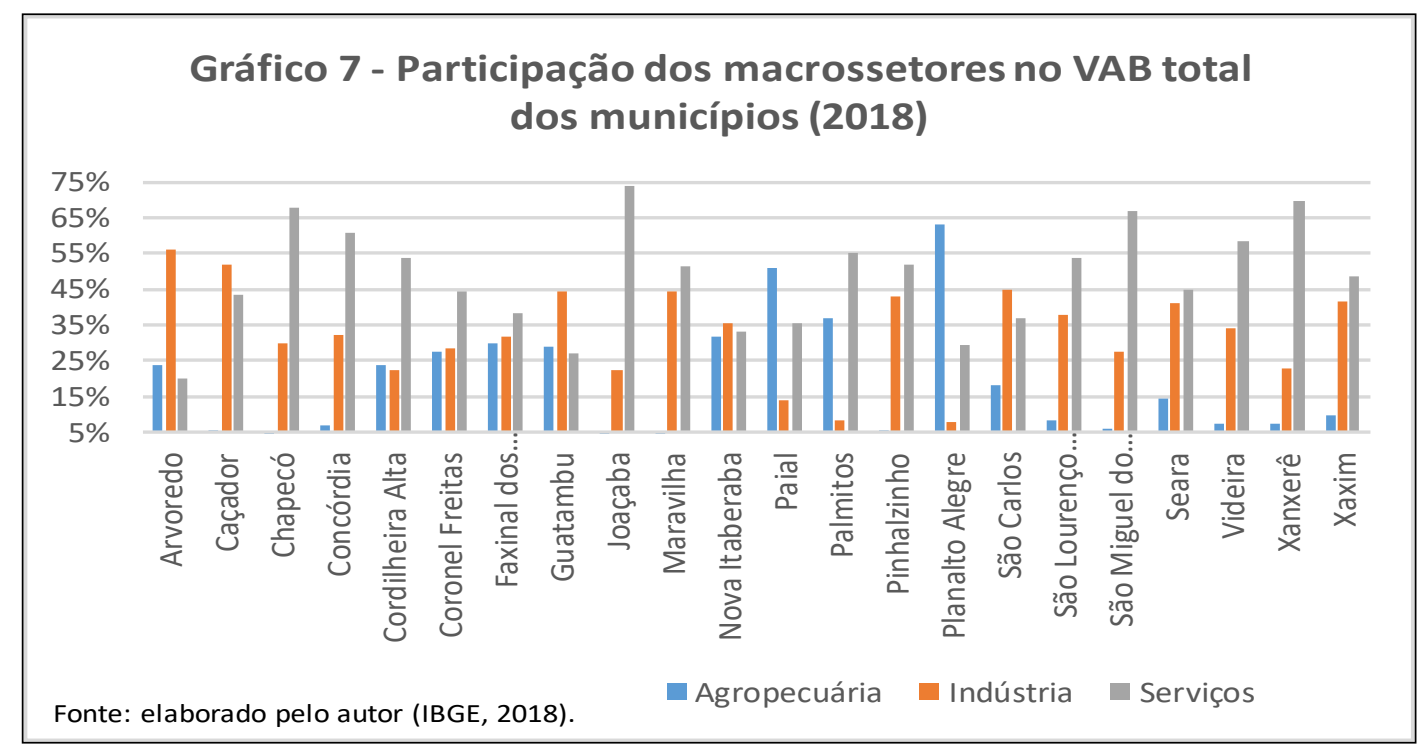

Referente ao crescimento da participação da indústria no VAB total, Arvoredo foi o município que mais se destacou, apresentando um crescimento de $419,80 \%$ de 2010 e 2018 (passando de 10,77\% para 55,96\%), seguido por Cordilheira Alta (crescimento de 34,76\%), Guatambu (37,04\%), Seara (26,30\%), Paial (106,46\%), Caçador (12,25\%), Concórdia (10,38\%), São Carlos (46,92\%) e Maravilha (15,20\%). Planalto Alegre, Palmitos, Faxinal dos Guedes, Xanxerê, São Miguel do Oeste, Joaçaba, Pinhalzinho, Chapecó, tiveram uma redução na participação da indústria no VAB total de $-80,02 \%,-39,86 \%,-35,15 \%,-29,85 \%,-15,73 \%,-10,00 \%,-3,28 \%,-1,01 \%$, respectivamente (Tabela 1). Para os municípios da região, o setor agropecuário concentrou redução expressiva na participação no VAB total.

Na tabela 1, o comparativo das participações relativas do VAB, entre os anos 2010 e 2018. Quanto à apropriação e geração de renda, é possível identificar através da relação Rendimento Domiciliar (RD) Anual per capita/PIB per capita, o percentual de apropriação da renda gerada por parte dos indivíduos de uma determinada região. 
Tabela 1 - Indicadores de macroespecialização dos municípios da região de pesquisa nas Produções Agropecuária, Industrial e de Serviços - Participação dos macrossetores no VAB total dos municípios - 2010/2018 -

\begin{tabular}{|c|c|c|c|c|c|c|c|c|c|}
\hline \multirow[b]{2}{*}{ Municípios } & \multicolumn{2}{|c|}{ Agropecuária } & \multirow{2}{*}{$\% \Delta$} & \multicolumn{2}{|c|}{ Indústria } & \multirow{2}{*}{$\% \Delta$} & \multicolumn{2}{|c|}{ Serviços } & \multirow{2}{*}{$\% \Delta$} \\
\hline & 2010 & 2018 & & 2010 & 2018 & & 2010 & 2018 & \\
\hline Arvoredo & $66,76 \%$ & $23,93 \%$ & $-64,16$ & $10,77 \%$ & $55,96 \%$ & 419,80 & $22,47 \%$ & $20,11 \%$ & $-10,53$ \\
\hline Caçador & $11,72 \%$ & $5,13 \%$ & $-56,22$ & $45,99 \%$ & $51,63 \%$ & 12,25 & $42,29 \%$ & $43,24 \%$ & 2,26 \\
\hline Chapecó & $3,26 \%$ & $2,12 \%$ & $-35,01$ & $30,24 \%$ & $29,93 \%$ & $-1,01$ & $66,51 \%$ & $67,95 \%$ & 2,17 \\
\hline Concórdia & $11,24 \%$ & $7,10 \%$ & $-36,81$ & $29,22 \%$ & $32,26 \%$ & 10,38 & $59,54 \%$ & $60,64 \%$ & 1,86 \\
\hline Cordilheira Alta & $10,99 \%$ & $23,74 \%$ & 116,02 & $16,60 \%$ & $22,37 \%$ & 34,76 & $72,41 \%$ & $53,89 \%$ & $-25,58$ \\
\hline Coronel Freitas & $38,42 \%$ & $27,57 \%$ & $-28,23$ & $24,78 \%$ & $28,25 \%$ & 13,99 & $36,80 \%$ & $44,18 \%$ & 20,05 \\
\hline Faxinal dos Guedes & $23,40 \%$ & $29,85 \%$ & 27,57 & $49,01 \%$ & $31,78 \%$ & $-35,15$ & $27,59 \%$ & $38,37 \%$ & 39,05 \\
\hline Guatambu & $23,82 \%$ & $28,69 \%$ & 20,46 & $32,41 \%$ & $44,41 \%$ & 37,04 & $43,77 \%$ & $26,90 \%$ & $-38,55$ \\
\hline Joaçaba & $5,79 \%$ & $3,63 \%$ & $-37,33$ & $24,95 \%$ & $22,46 \%$ & $-10,00$ & $69,25 \%$ & $73,91 \%$ & 6,73 \\
\hline Maravilha & $5,80 \%$ & $4,22 \%$ & $-27,17$ & $38,54 \%$ & $44,40 \%$ & 15,20 & $55,66 \%$ & $51,38 \%$ & $-7,70$ \\
\hline Nova ltaberaba & $35,15 \%$ & $31,54 \%$ & $-10,27$ & $32,52 \%$ & $35,37 \%$ & 8,75 & $32,33 \%$ & $33,09 \%$ & 2,37 \\
\hline Paial & $66,89 \%$ & $50,92 \%$ & $-23,88$ & $6,67 \%$ & $13,78 \%$ & 106,46 & $26,44 \%$ & $35,30 \%$ & 33,54 \\
\hline Palmitos & $41,30 \%$ & $36,68 \%$ & $-11,17$ & $13,86 \%$ & $8,34 \%$ & $-39,86$ & $44,84 \%$ & $54,98 \%$ & 22,61 \\
\hline Pinhalzinho & $6,02 \%$ & $5,17 \%$ & $-14,09$ & $44,52 \%$ & $43,06 \%$ & $-3,28$ & $49,47 \%$ & $51,77 \%$ & 4,66 \\
\hline Planalto Alegre & $22,41 \%$ & $63,12 \%$ & 181,63 & $38,10 \%$ & $7,61 \%$ & $-80,02$ & $39,49 \%$ & $29,27 \%$ & $-25,88$ \\
\hline São Carlos & $26,46 \%$ & $18,07 \%$ & $-31,70$ & $30,60 \%$ & $44,96 \%$ & 46,92 & $42,94 \%$ & $36,97 \%$ & $-13,91$ \\
\hline São Lourenço do Oes & $13,59 \%$ & $8,51 \%$ & $-37,40$ & $31,78 \%$ & $37,99 \%$ & 19,54 & $54,63 \%$ & $53,50 \%$ & $-2,06$ \\
\hline São Miguel do Oeste & $4,10 \%$ & $5,78 \%$ & 41,06 & $32,74 \%$ & $27,59 \%$ & $-15,73$ & $63,16 \%$ & $66,62 \%$ & 5,49 \\
\hline Seara & $22,02 \%$ & $14,31 \%$ & $-35,00$ & $32,49 \%$ & $41,03 \%$ & 26,30 & $45,49 \%$ & $44,65 \%$ & $-1,84$ \\
\hline Videira & $9,39 \%$ & $7,31 \%$ & $-22,15$ & $30,92 \%$ & $34,25 \%$ & 10,76 & $59,68 \%$ & $58,44 \%$ & $-2,09$ \\
\hline Xanxerê & $9,20 \%$ & $7,52 \%$ & $-18,19$ & $32,71 \%$ & $22,95 \%$ & $-29,85$ & $58,09 \%$ & $69,53 \%$ & 19,69 \\
\hline Xaxim & $17,20 \%$ & $9,65 \%$ & $-43,92$ & $41,03 \%$ & $41,74 \%$ & 1,73 & $41,76 \%$ & $48,61 \%$ & 16,39 \\
\hline Região de Pesquisa & $10,07 \%$ & $7,12 \%$ & $-29,33$ & $32,83 \%$ & $33,59 \%$ & 2,31 & $57,10 \%$ & $59,29 \%$ & 3,84 \\
\hline
\end{tabular}

Fonte: IBGE/Coordenação de Contas Nacionais, Sistema de Contas Regionais.

Nota: 1) Estrutura do Valor Adicionado Bruto (2010, 2018); (1) Agropecuária; (2) Indústria; (3) Serviços.

Para isto, com base na tabela 2, é possível identificar o percentual de apropriação da renda para a região de pesquisa. Ao analisar a relação Rendimento Domiciliar (RD) Anual per capita/PIB per capita, depara-se com um percentual de apropriação da renda por parte dos indivíduos da região de pesquisa de 16,41\% em 2010 e 8,47\% em 2018. Essa redução (de 16,41\% para $8,47 \%$ ) observada na região como um todo, também se verifica na comparação individual de cada um dos municípios no mesmo período, assim como para o Estado de Santa Catarina. Tal fenômeno pode ser considerado um indício de aumento na desigualdade social, embora, devido a carência de uma base de dados mais extensa, não seja possível identificar a causa do fenômeno, nem mesmo se este é uma tendência ou um evento isolado. 


\begin{tabular}{|c|c|c|c|c|c|c|c|c|c|c|c|c|c|c|}
\hline Municíios & $\begin{array}{c}\text { População } \\
\text { Total (ñ } \\
\text { habitantes) } \\
2010\end{array}$ & $\begin{array}{c}\text { População } \\
\text { Total (ñ } \\
\text { habitantes) } \\
2020\end{array}$ & $\begin{array}{c}\text { Pop } \\
\text { rura//Pop } \\
\text { Total (\%)- } \\
\text { 2010/2020 }\end{array}$ & $\begin{array}{c}\text { VAB Agrop./ } \\
\text { VAB Total - } \\
2018 \text { - } \\
\text { Dados do } \\
\text { Municipal } \\
(\%)(1) \\
\end{array}$ & \begin{tabular}{|c|} 
VAB \\
Ind./NAB \\
Total - 2018. \\
Dados do \\
Municipal \\
$(\%)(2)$ \\
\end{tabular} & $\begin{array}{c}\text { VAB } \\
\text { Serv./NAB } \\
\text { Total - } 2018 . \\
\text { Dados do } \\
\text { Municipal } \\
(\%)(3) \\
\end{array}$ & $\begin{array}{c}\text { PIB Per Capita - } \\
2017 \\
\text { população/2010 } \\
-(\text { RȘ })(4)\end{array}$ & \begin{tabular}{|c|} 
PIB Per Capita - \\
2017 \\
população/2020 \\
-(RSS|(4)
\end{tabular} & $\begin{array}{c}\text { Rendimento } \\
\text { Domiclilar } \\
\text { Anual per capita } \\
-2010 \text { - }(\mathbb{R} \$)^{(5)}\end{array}$ & \begin{tabular}{|c|} 
Rendimento \\
Domiciliar Anual \\
per capita - 2020- \\
$(\mathbb{R} S)^{(5)}$
\end{tabular} & $\% \Delta$ & $\begin{array}{c}\text { Rendimento } \\
\text { Anual } \\
\text { Total2010/PIB } \\
(\%)\end{array}$ & $\begin{array}{c}\text { Rendimento } \\
\text { Anual } \\
\text { Total2020/PIB } \\
(\%)\end{array}$ & $\% \Delta$ \\
\hline Arvoredo & 2260 & 2234 & 77,83 & 23,93 & 55,96 & 20,11 & 17335,84 & 44925,17 & 2286,98 & $2.313,59$ & 1,16 & 13,19 & 5,15 & $-60,96$ \\
\hline Caçador & 70762 & 79313 & 8,91 & 5,13 & 51,63 & 43,24 & 21684,79 & 41593,02 & 3310,33 & $2.953,43$ & $-10,78$ & 15,27 & 7,10 & $-53,49$ \\
\hline Chapecó & 183530 & 224013 & 8,40 & 2,12 & 29,93 & 67,95 & 25087,44 & 42865,09 & 4367,60 & $3.578,30$ & $-18,07$ & 17,41 & 8,35 & $-52,05$ \\
\hline Concórdia & 68621 & 75167 & 20,05 & 7,10 & 32,26 & 60,64 & 24336,01 & 44559,20 & 4428,88 & $4.043,18$ & $-8,71$ & 18,20 & 9,07 & $-50,14$ \\
\hline $\begin{array}{r}\text { Cordilheira } \\
\text { Alta } \\
\end{array}$ & 3767 & 4520 & 61,56 & 23,74 & 22,37 & 53,89 & 50264,40 & 56859,86 & 2964,27 & $2.470,45$ & $-16,66$ & 5,90 & 4,34 & $-26,33$ \\
\hline $\begin{array}{r}\text { Coronel } \\
\text { Freitas } \\
\end{array}$ & 10213 & 9940 & 40,60 & 27,57 & 28,25 & 44,18 & 15096,54 & 27162,77 & 2749,85 & $2.825,37$ & 2,75 & 18,22 & 10,40 & $-42,90$ \\
\hline $\begin{array}{r}\text { Faxinal dos } \\
\text { Guedes } \\
\end{array}$ & 10661 & 10649 & 27,61 & 29,85 & 31,78 & 38,37 & 30489,54 & 41379,43 & 3285,12 & $3.288,83$ & 0,11 & 10,77 & 7,95 & $-26,23$ \\
\hline Guatambu & 4679 & 4698 & 62,62 & 28,69 & 44,41 & 26,90 & 37965,16 & 48165,23 & 2842,59 & $2.831,10$ & $-0,40$ & 7,49 & 5,88 & $-21,50$ \\
\hline Joaçaba & 27020 & 30404 & 7,76 & 3,63 & 22,46 & 73,91 & 34491,64 & 63447,70 & 6128,54 & $5.446,43$ & $-11,13$ & 17,77 & 8,58 & $-51,69$ \\
\hline Maravilha & 22101 & 26116 & 18,16 & 4,22 & 44,40 & 51,38 & 28401,57 & 49342,87 & 4163,13 & $3.523,11$ & $-15,37$ & 14,66 & 7,14 & $-51,29$ \\
\hline $\begin{array}{r}\text { Nova } \\
\text { Itaberaba }\end{array}$ & 4267 & 4329 & 64,14 & 31,54 & 35,37 & 33,09 & 22337,47 & 24765,72 & 3158,69 & $3.113,46$ & $-1,43$ & 14,14 & 12,57 & $-11,10$ \\
\hline Paial & 1763 & 1474 & 80,94 & 50,92 & 13,78 & 35,30 & 12650,03 & 27865,56 & 2621,17 & $3.135,09$ & 19,61 & 20,72 & 11,25 & $-45,70$ \\
\hline Palmitos & 16020 & 16157 & 38,38 & 36,68 & 8,34 & 54,98 & 20282,83 & 38438,17 & 3707,65 & $3.676,21$ & $-0,85$ & 18,28 & 9,56 & $-47,68$ \\
\hline Pinhalzinho & 16332 & 20712 & 16,64 & 5,17 & 43,06 & 51,77 & 33466,75 & 54203,46 & 3870,24 & $3.051,80$ & $-21,15$ & 11,56 & 5,63 & $-51,31$ \\
\hline $\begin{array}{r}\text { Planalto } \\
\text { Alegre }\end{array}$ & 2654 & 2888 & 59,80 & 63,12 & 7,61 & 29,27 & 25451,02 & 32848,75 & 2908,48 & $2.672,82$ & $-8,10$ & 11,43 & 8,14 & $-28,80$ \\
\hline São Carlos & 10291 & 11369 & 32,93 & 18,07 & 44,96 & 36,97 & 19051,99 & 37348,39 & 3750,43 & $3.394,82$ & $-9,48$ & 19,69 & 9,09 & $-53,83$ \\
\hline $\begin{array}{r}\text { São Lourenço } \\
\text { do Oeste } \\
\end{array}$ & 21792 & 24291 & 22,54 & 8,51 & 37,99 & 53,50 & 20692,00 & 39555,14 & 3520,51 & $3.158,33$ & $-10,29$ & 17,01 & 7,98 & $-53,07$ \\
\hline $\begin{array}{r}\text { São Miguel do } \\
\text { Oeste }\end{array}$ & 36306 & 40868 & 11,68 & 5,78 & 27,59 & 66,62 & 24736,05 & 37241,17 & 4972,30 & $4.417,26$ & $-11,16$ & 20,10 & 11,86 & $-40,99$ \\
\hline Seara & 16936 & 17576 & 31,59 & 14,31 & 41,03 & 44,65 & 28032,53 & 45511,64 & 4702,19 & $4.530,97$ & $-3,64$ & 16,77 & 9,96 & $-40,65$ \\
\hline Videira & 47188 & 53610 & 9,18 & 7,31 & 34,25 & 58,44 & 28014,11 & 45287,53 & 4418,40 & $3.889,11$ & $-11,98$ & 15,77 & 8,59 & $-45,55$ \\
\hline Xanxerê & 44128 & 51642 & 11,30 & 7,52 & 22,95 & 69,53 & 23601,59 & 32990,79 & 3750,14 & $3.204,49$ & $-14,55$ & 15,89 & 9,71 & $-38,87$ \\
\hline Xaxim & 25713 & 28983 & 18,46 & 9,65 & 41,74 & 48,61 & 22531,37 & 32702,79 & 3208,06 & $2.846,11$ & $-11,28$ & 14,24 & 8,70 & $-38,88$ \\
\hline $\begin{array}{r}\text { Região de } \\
\text { Pesquisa }\end{array}$ & 647004 & 740953 & 15,32 & 7,12 & 33,59 & 59,29 & 25151,36 & 42561,64 & 4127,42 & $3.604,09$ & $-12,68$ & 16,41 & 8,47 & $-48,40$ \\
\hline $\begin{array}{r}\text { Santa } \\
\text { Catarina }\end{array}$ & 6248436 & 7252502 & 16,01 & 6,44 & 31,21 & 62,36 & 24602,32 & 41120,57 & 6779,62 & $5.841,02$ & $-13,84$ & 27,56 & 14,20 & $-48,45$ \\
\hline
\end{tabular}

Fonte: IBGE, Censo Demográfico 2010; IBGE. Estimativa de população (2020); Diretoria de Contas Nacionais.

Nota: VAB - Valor Adicionado Bruto (2018); (1) Valor Adicionado Bruto da Agropecuária; (2) Valor Adicionado Bruto da Indústria; (3) Valor Adicionado Bruto de Serviçcos;

(4) Produto Interno Bruto (2018); (5) Exclusive o rendimento das pessoas cuja condição no domiclio era: pensionista, empregado(a) doméstico(a) ou parente do

empregado(a) doméstico(a).

Logo, para fins economicistas esta questão exigiria uma nova pesquisa com vista a identificação da causalidade do fenômeno. $O$ indicador que apresenta um desvio padrão relativo de $2,10 \%$ e uma medida de variação relativa de $24,71 \%$ considerada de média dispersão ${ }^{5}$ revela

${ }^{5}$ Coeficiente de variação (cv): baixa dispersão (cv $\left.\leq 15 \%\right)$; média dispersão $(15 \%<c v<30 \%$ ); alta dispersão (cv $\geq$ $30 \%)$. 
seu significado ao tomarem-se os municípios como referência, o que revela que a região apresenta proporção média de desigualdades regionais no que diz respeito à geração e apropriação de renda.

Conforme Paiva (2004, p. 35), essas diferenças são explicadas pelas desigualdades no grau de controle dos agentes residentes sobre o excedente operacional gerado na região e sobre a carga tributária incidente sobre as atividades realizadas internamente. Se for simulada uma retirada dos valores extremos (Cordilheira Alta, 4,34\% e Nova Itaberaba, 12,57\%), os novos extremos seriam 5,15\% e 11,86\%, respectivamente, Arvoredo e São Miguel do Oeste. Teríamos um desvio padrão relativo de $1,76 \%$, e uma medida de dispersão relativa de $20,68 \%$, também considerada média, o que aponta para a existência média de desigualdades regionais ${ }^{6}$.

Por fim, para que se tenha melhores pistas do potencial da região faz-se necessário o uso da racionalidade do Quociente Locacional calculado a partir do VAB por macrossetor produtivo, para fins de mensurar o grau de especialização relativa da região (Tabela 3). Para isto, adotou-se neste estudo duas situações em que a medida de especialização se aplica a uma região de referência.

A tabela 4, apresenta os QLs dos municípios tendo como referência a regiao de pesquisa. Já, na tabela 5 são apresentados os QLs dos municípios e da região de pesquisa, tendo como referência o Estado de Santa Catarina. Os QLs foram calculados a partir de dados da tabela 3, tendo 2018 como ano de referência (o IBGE possui dados atualizados do VAB, somente até o ano de 2018). Para fins de interpretação, adota-se: para QLs $\leq 1$, como sinônimo de não especialização relativa e QLs > 1 como sinônimo de especialização relativa, sendo que quanto maior o QL, maior será a especialização relativa de um setor em detrimento da região de referência.

De acordo com a tabela 4, que apresenta a medida de especialização relativa dos municípios tendo como referência a região de pesquisa, observa-se que o macrossetor produtivo agropecuário é o que apresenta maior especialização relativa por número de municípios, apresentando QL > 1 em 15 dos 22 municípios, enquanto o menor verificado foi para Chapecó que apresentou um QL agropecuário de 0,2973. Planalto Alegre, é o município que apresenta o QL agropecuário mais expressivo $(8,8645)$.

\footnotetext{
${ }^{6}$ Lembra-se que, no interior da região de pesquisa, há municípios que são polarizados por outros municípios que pertencem a regiões que não estão incluídas na pesquisa ou a outro Estado da Federação.
} 
Tabela 3 - Estrutura do VAB por macrossetor produtivo (x1000) - R\$ - 2018

\begin{tabular}{|c|c|c|c|c|}
\hline & VAB Agropecuaria & VAB Indústria & VAB Serviços & VAB Total \\
\hline Arvoredo & $19.413,87$ & $45.404,89$ & $16.313,41$ & $81.132,17$ \\
\hline Caçador & $129.558,66$ & $1.303 .678,85$ & $1.092 .045,55$ & $2.525 .283,06$ \\
\hline Chapecó & $155.164,16$ & $2.193 .690,00$ & 4.979.990,33 & $7.328 .844,49$ \\
\hline Concórdia & $183.350,20$ & $832.638,24$ & $1.565 .417,24$ & $2.581 .405,68$ \\
\hline Cordilheira Alta & $46.154,28$ & $43.495,71$ & $104.782,68$ & $194.432,67$ \\
\hline Coronel Freitas & $55.126,58$ & $56.478,95$ & $88.326,79$ & $199.932,32$ \\
\hline Faxinal dos Guedes & $97.587,33$ & $103.901,98$ & $125.419,06$ & $326.908,37$ \\
\hline Guatambu & $49.020,58$ & $75.875,97$ & $45.954,63$ & $170.851,18$ \\
\hline Joaçaba & $55.381,42$ & $342.486,35$ & $1.127 .133,05$ & $1.525 .000,82$ \\
\hline Maravilha & $41.772,30$ & $439.436,12$ & $508.452,73$ & $989.661,15$ \\
\hline Nova Itaberaba & $23.216,15$ & $26.036,86$ & $24.361,36$ & $73.614,37$ \\
\hline Paial & $13.380,85$ & $3.620,60$ & $9.277,84$ & $26.279,29$ \\
\hline Palmitos & $180.546,97$ & $41.032,81$ & $270.584,66$ & $492.164,44$ \\
\hline Pinhalzinho & $45.201,36$ & $376.620,06$ & $452.845,52$ & $874.666,94$ \\
\hline Planalto Alegre & $46.396,47$ & $5.594,50$ & $21.516,12$ & $73.507,09$ \\
\hline São Carlos & $60.953,30$ & $151.673,17$ & $124.692,25$ & $337.318,72$ \\
\hline São Lourenço do Oeste & $58.699,97$ & $262.066,34$ & $369.057,71$ & $689.824,02$ \\
\hline São Miguel do Oeste & $68.516,57$ & $326.818,05$ & $789.089,07$ & $1.184 .423,69$ \\
\hline Seara & $89.237,76$ & $255.851,29$ & $278.410,12$ & $623.499,17$ \\
\hline Videira & $136.187,64$ & $637.873,39$ & $1.088 .298,69$ & $1.862 .359,72$ \\
\hline Xanxerê & $97.648,23$ & $297.802,30$ & $902.264,81$ & $1.297 .715,34$ \\
\hline Xaxim & $68.049,75$ & $294.395,35$ & $342.817,73$ & $705.262,83$ \\
\hline Região de Pesquisa & $1.720 .564,40$ & 8.116.471,78 & $14.327 .051,35$ & $24.164 .087,53$ \\
\hline Santa Catarina & $13.671 .000,00$ & $66.294 .000,00$ & $132.462 .000,00$ & 212.427.000,00 \\
\hline
\end{tabular}

Fonte: IBGE Cidades (2020, base 2018).

Tabela 4 - Medida de especialização (QL) por macrossetor produtivo dos

municípios em relação à região de pesquisa

\begin{tabular}{|c|c|c|c|}
\hline & VAB Agropecuaria & VAB Indústria & VAB Serviços \\
\hline Arvoredo & 3,3606 & 1,6661 & 0,3391 \\
\hline Caçador & 0,7205 & 1,5370 & 0,7294 \\
\hline Chapecó & 0,2973 & 0,8911 & 1,1461 \\
\hline Concórdia & 0,9975 & 0,9603 & 1,0228 \\
\hline Cordilheira Alta & 3,3338 & 0,6660 & 0,9089 \\
\hline Coronel Freitas & 3,8724 & 0,8410 & 0,7451 \\
\hline Faxinal dos Guedes & 4,1924 & 0,9462 & 0,6471 \\
\hline Guatambu & 4,0296 & 1,3222 & 0,4537 \\
\hline Joaçaba & 0,5100 & 0,6686 & 1,2466 \\
\hline Maravilha & 0,5928 & 1,3219 & 0,8665 \\
\hline Nova Itaberaba & 4,4292 & 1,0530 & 0,5582 \\
\hline Paial & 7,1510 & 0,4102 & 0,5955 \\
\hline Palmitos & 5,1520 & 0,2482 & 0,9273 \\
\hline Pinhalzinho & 0,7258 & 1,2819 & 0,8732 \\
\hline Planalto Alegre & 8,8645 & 0,2266 & 0,4937 \\
\hline São Carlos & 2,5378 & 1,3387 & 0,6235 \\
\hline São Lourenço do Oeste & 1,1951 & 1,1310 & 0,9023 \\
\hline São Miguel do Oeste & 0,8124 & 0,8215 & 1,1237 \\
\hline Seara & 2,0101 & 1,2217 & 0,7531 \\
\hline Videira & 1,0270 & 1,0197 & 0,9856 \\
\hline Xanxerê & 1,0568 & 0,6832 & 1,1726 \\
\hline Xaxim & 1,3551 & 1,2427 & 0,8198 \\
\hline
\end{tabular}

Fonte: IBGE Cidades (2020, base 2018). 
Conforme a tabela 5, que apresenta a medida de especialização relativa dos municípios e da região de pesquisa tendo como referência o Estado de Santa Catarina, observa-se que o macrossetor da agropecuário é o que apresenta maior especialização relativa por número de municípios, novamente, apresentando QL > 1 em 16 dos 22 municípios.

Tabela 5 - Medida de especialização (QL) por macrossetor produtivo da região de pesquisa e dos municípios em relação ao Estado de Santa Catarina

\begin{tabular}{l|c|c|c}
\hline & VAB Agropecuaria & VAB Indústria & VAB Serviços \\
\hline Arvoredo & 3,7182 & 1,7933 & 0,3225 \\
\hline Caçador & 0,7972 & 1,6542 & 0,6935 \\
\hline Chapecó & 0,3290 & 0,9591 & 1,0897 \\
\hline Concórdia & 1,1037 & 1,0336 & 0,9725 \\
\hline Cordilheira Alta & 3,6885 & 0,7168 & 0,8642 \\
\hline Coronel Freitas & 4,2844 & 0,9052 & 0,7085 \\
\hline Faxinal dos Guedes & 4,6385 & 1,0184 & 0,6153 \\
\hline Guatambu & 4,4583 & 1,4231 & 0,4313 \\
\hline Joaçaba & 0,5643 & 0,7196 & 1,1853 \\
\hline Maravilha & 0,6559 & 1,4228 & 0,8239 \\
\hline Nova Itaberaba & 4,9005 & 1,1333 & 0,5307 \\
\hline Paial & 7,9119 & 0,4415 & 0,5662 \\
\hline Palmitos & 5,7002 & 0,2672 & 0,8817 \\
\hline Pinhalzinho & 0,8030 & 1,3797 & 0,8303 \\
\hline Planalto Alegre & 9,8077 & 0,2439 & 0,4694 \\
\hline São Carlos & 2,8078 & 1,4408 & 0,5928 \\
\hline São Lourenço do Oeste & 1,3222 & 1,2173 & 0,8580 \\
\hline São Miguel do Oeste & 0,8989 & 0,8842 & 1,0684 \\
\hline Seara & 2,2239 & 1,3149 & 0,7161 \\
\hline Videira & 1,1363 & 1,0975 & 0,9371 \\
\hline Xanxerê & 1,1692 & 0,7353 & 1,1150 \\
\hline Xaxim & 1,4993 & 1,3376 & 0,7795 \\
\hline Região de Pesquisa & 1,1064 & 1,0763 & 0,9508 \\
\hline Fonte:IBGE Cidades & $2018)$ & & \\
\hline & & & \\
\hline
\end{tabular}

Fonte: IBGE Cidades (2020, base 2018).

Entre os QLs > 1, Planalto Alegre, novamente, é o município que apresentou o maior QL do agropecuário $(9,8077)$. Por outro lado, foram registrados 6 municípios com $Q L s<1$, sendo eles, Chapecó (0,3290), Caçador (0,7972), Joaçaba (0,5643), Maravilha (0,6559), Pinhalzinho $(0,8030)$ e São Miguel do Oeste (0,8989). A Indústria apresentou QL`s > 1 em 13 municípios, com destaque para Arvoredo (1,7933), Caçador (1,6542), Guatambu (1,4231), Maravilha $(1,4228)$, São Carlos (1,4408), Pinhalzinho $(1,3797)$, Seara $(1,3149)$ e Xaxim $(1,3376)$. Já, o macrossetor de serviços, apresentou QL`s > 1 em somente 4 municípios, sendo eles Joaçaba $(1,1853)$, Chapecó $(1,0897)$, Xanxerê $(1,1150)$ e São Miguel do Oeste $(1,0684)$. A região de pesquisa apresentou QL 
$>1$ nos macrossetores agropecuário $(1,1064)$ e indústria $(1,0763)$, enquanto o macrossetor de serviço registrou QL de 0,9508.

\section{Apresentação e discussão dos dados}

Identificar o potencial de uma região, com vista ao planejamento para o desenvolvimento endógeno tem como ponto de partida a identificação dos fatores produtivos que a região possuí e que se encontra subutilizado ou utilizado de forma subótima. Uma vez identificados, faz-se necessária a mensuração do capital social, humano e institucional com vista à mobilização político-econômica local, na qual torna-se possível o processo de endogenização da geração e distribuição da riqueza por parte dos agentes locais. Assim pressupõe-se que os agentes locais, ao interagir em laços de cooperação local/regional possam se tornar protagonistas do desenvolvimento econômico-social da região.

Uma análise dos dados apresentados no item 5.1, exige primeiramente a categorização da região e seus municípios quanto a sua tipicidade dada sua estrutura produtiva com base no peso relativo de cada macrossetor. Isto tem como objetivo verificar em quais setores residem as principais suspeitas de potencial. Primeiramente descarta-se a possibilidade da região e seus municípios serem tipicamente rurais, uma vez que segundo Paiva (2004), as regiões tipicamente rurais apresentam participação do VAB agropecuária/VAB total, superior a 30\% (na Tabela 1, somente 7 municípios possui VAB agropecuária/VAB total $>30 \%$ ). A próxima suspeita de potencial reside no setor industrial, a partir do qual, segundo Paiva (2004), pode-se passar a suspeitar da existência de potencialidades imediatas na indústria regional quando a relação VAB industrial/VAB total é superior a 25\%, o que de acordo com os Gráficos 3, 6 e 7 se verifica na região e em todos os seus municípios com exceção de Planalto Alegre $(7,61 \%)$, Paial $(13,78 \%)$ e Palmitos (8,34\%) (2018).

Ainda de acordo com os Gráficos 3, 6 e 7, é possível verificar a expressiva relação VAB serviços/VAB total na região e nos municípios. Esta relação é na região (e quase sempre nos municípios) superior a 47\%, o que segundo Paiva (2004) pode representar a estruturalidade da crise produtiva da economia regional. Num primeiro momento a questão não pode ser encarada como sentença final da análise de desenvolvimento regional uma vez que a expressiva participação do setor serviços no VAB total, pode se caracterizar em dois sentidos no que diz respeito a produtividade no setor: 
[...] de um lado, uma elevada produtividade em serviços - particularmente quando a medida é captada para municípios que já são (ou estão se constituindo como) pólos regionais - é um indicador de possibilidade de expansão da rede de serviços interna com vistas a atender a demandas da periferia regional; de outro lado, uma produtividade particularmente baixa no setor serviços pode ser a expressão de um gargalo limitador da dinâmica regional. Particularmente, os municípios e as microrregiões que se encontram relativamente afastados dos polos consumidores responsáveis pela absorção de sua produção mercantil de exportação precisam contar com serviços de comercialização e transporte suficientemente produtivos e econômicos para contrabalançar as desvantagens nos custos de transporte (PAIVA, 2004, p.31).

Pesquisas anteriores (MAIA, SANTIN, ALBA e VILLELA, 2014; MAIA e LUDWIG, 2013), mostram a importância da agroindústria na região, a qual é capaz de promover a integração entre os setores agropecuário, indústria e serviços. Este processo de integração tem trabalhado na formação e consolidação de clusters regionais.

A integração entre os setores agropecuário, indústria e serviços, bem como a característica de micropólos regionais que os municípios assumem no oeste catarinense, pode ser um indício da capacidade de expansão do setor serviços na região. Neste caso a elevada participação na relação VAB serviços/VAB total, perde sua característica de gargalo e passa a ser considerado como agente potencializador do desenvolvimento regional. Como prova disso, a Tabela 5, mostra que apesar da elevada relação VAB serviços/VAB total, o setor que apresentam o maior número de QLs > 1 é o agropecuário seguida pelo setor indústria. Enquanto o setor serviços apresentou QL > 1 em apenas 4 municípios (Joaçaba $(1,1853)$, Chapecó $(1,0897)$, Xanxerê $(1,1150)$ e São Miguel do Oeste $(1,0684)$, a região de pesquisa por si só apresentou QL > 1 na agropecuária $(1,1064)$ e indústria $(1,0763)$.

Quanto a categorização da região, pode-se lançar luz sobre o fato dessa ser uma região que vêm se consolidando como agroindustrial, primeiramente por ser responsável por 12,59\% do VAB da agropecuária e $12,24 \%$ do VAB da indústria no estado de Santa Catarina (Gráfico 1), mesmo sendo composta por apenas 22 municípios dentre os 295 do total estadual. Em seguida, observa-se que a indústria corresponde a mais de $31,21 \%$ do VAB total da região (Tabela 2). Por fim, a agropecuária $(1,1064)$ e a indústria $(1,0763)$ foram setores produtivos que apresentaram QL > 1 para a região de pesquisa na análise região de pesquisa tendo como referência Santa Catarina (Tabela 5). 


\section{Considerações finais}

A caracterização da região como agroindustrial não menospreza a agropecuário ou o rural, uma vez que ambos estão interligados e o sucesso da indústria na região está intimamente ligado à formação dos clusters agroindustriais.

Neste estudo, identificou-se potencialidades no setor industrial e serviço na RMChap, setores que vêm ganhando espaço na economia regional nas últimas décadas. Na RMChap, dada a expansão da ocupação populacional, das atividades econômicas e intensa urbanização, há forte tendência a expansão do setor de serviço decorrente das aglomerações urbanas e urbanização das áreas rurais.

A RMChap é polarizada diretamente por Chapecó e um conjunto de cidades que, por sua vez são polarizadoras ou exercem influência em outras cidades, como por exemplo Concórdia e São Miguel do Oeste, ou ainda outras centralidades constituídas na região metropolitana, como Xanxerê, Maravilha e Pinhalzinho.

Mesmo que a relação Rendimento Domiciliar (RD) Anual per capita/PIB per capita, seja complementar, indicando a existência de disparidade interna entre os diversos municípios (Tabelas 2), num primeiro momento o que interessou é identificar os setores que apresentam maior potencial, baseado no estudo dos QLs e do VAB. Uma vez identificado quais os setores que possuem o maior potencial em uma região, pode-se partir para uma análise específica destes com base em novas pesquisas, com vista a identificação de novas potencialidades e gargalos ao desenvolvimento regional endógeno.

Quando houve o maior crescimento da cidade Chapecó/SC, os municípios não possuíam condições para viabilizar e prover as cidades na mesma rapidez com que consolidava o seu núcleo urbano, além do fato que, nesta época, não era preocupação corrente dos poderes públicos o enfrentamento da exclusão social. Desta forma, a desigualdade socioespacial já se faz evidente na paisagem da cidade de Chapecó/SC, com a formação de bairros operários reduzida, mas crescente infraestrutura, assentamentos precários e o despejo de algumas populações excluídas.

No tocante à região de pesquisa (RMChap), sobretudo na análise dos territórios urbanizados em seu conjunto, se verifica uma reorganização que favorece as cidades menores e cada vez mais situadas dentro de um mesmo mecanismo de funcionamento metropolitano, ou seja, de migrações alternadas e relações econômicas e sociais cotidianas em um mesmo espaço metropolitano. Transformações que expressam uma recomposição funcional e social dos espaços metropolitanos (ASCHER, 1995, p.19). Então, inspirado em Benfatti, Queiroga e Silva 
(2010, p.32), observa-se a formação de uma entidade urbana nova..., mas não uma megalópole como apontam os autores, mas especificamente, um território que tem adquirido densidade técnico-científico-informacional e comunicacional.

\section{Referências}

ABRAMOVAY, Ricardo. (Org). Para uma teoria dos estudos territoriais. In: ORTEGA, Antonio César; FILHO, Niemeyer Almeida. Desenvolvimento territorial, segurança alimentar e economia solidária. Campinas: Alínea, 2007.

ASCHER, F. Métapolis ou l'avenir des villes. Paris: Odile Jacob, 1995.

Atlas Socioeconômico do Rio Grande do Sul. Secretaria de Planejamento, Orçamento e Gestão. 4 ed. Porto Alegre: SEPLAG, 2019.

BENFATTI, Denio M.; QUEIROGA, Eugenio F.; SILVA, Jonathas M. Transformações da metrópole contemporânea: novas dinâmicas espaciais, esfera da vida pública e sistemas de espaços livres. Revista Brasileira de Estudos Urbanos e Regionais. v.12. n.1. p.29-43. mai.2010.

BECKER, Dizimar Fermiano. A economia política do (des)envolvimento regional. Redes. v.7, n.3. p.35-59, set./dez.2002.

BENKO, Georges. 1999. Economia, espaço e globalização na aurora do século XXI. São Paulo, Hucitec, 226 p.

BOISIER, Sérgio. Em busca do esquivo desenvolvimento regional: entre a caixa-preta e o projeto político. Revista Planejamento e Políticas Públicas. n.13 - Jun.1996.

BREITBACH, Áurea. Estudo sobre o conceito de região. Porto Alegre: FEE, 1988.

COSTA, José Silva; DENTINHO, Tomaz Ponce; PETER, Nijkamp. Compêndio de economia regional. Volume II, Métodos e técnicas de análise regional. Parede-Portugal: Principia, 2011.

COSTA, José Silva; NIJKAMP, Peter. Compêndio de economia regional. Volume I, Teoria, temáticas e políticas. Cascais: Princípia, 2009.

DELGADO, Ana Paula; GODINHO, Isabel Maria. Medidas de localização e de especialização regional. In: COSTA, José Silva; DENTINHO, Tomaz Ponce; PETER, Nijkamp. Compêndio de economia regional. Volume II, Métodos e técnicas de análise regional. Parede-Portugal: Principia, 2011.

DINIZ, Clélio Campolina; CROCCO, Marco. Economia Regional e Urbana: contribuições teóricas recentes. Minas Gerais: Editora UFMG, 2006.

DINIZ, Clélio Campolina. Global-Local: interdependências e desigualdades ou notas para uma política tecnológica e industrial regionalizada no Brasil. Rio de Janeiro, CEDEPLAR/IE/UFRJ, 2000.

FUJITA, Camila, MATIELLO, Alexandre, ALBA, Rosa Salete. Rede de polo e micropolos regionais no oeste catarinense. Redes. v.14, n.2, mai./ago., 2009.

HADDAD, Paulo R. (org.) Economia Regional: teorias e métodos de análise. Fortaleza: BNB, 1989. 
IBGE. Instituto Brasileiro de Geografia e Estatística. Regiões de Influência das Cidades 2007. Rio de Janeiro: IBGE, 2007.

MACEDO, Guilherme; MONASTERIO, Leonardo. Local Multiplier of Industrial Employment: Brazilian Mesoregions (2000-2010). Revista de Economia Política (Impresso), v. 36, p. 827-839, 2016.

MAIA, Claudio Machado; SANTIN, Myriam Aldana. A cidade inteligente e sua influência regional. In: XVIII ENANPUR, Associação Nacional de Pós-Graduação e Pesquisa em Planejamento Urbano e Regional. Natal/RN: Praiamar Natal Hotel\&Convention, 2019a.

MAIA, Claudio Machado; VILLELA, Ana Laura Vianna; ALBA, Rosa Salete; ARRUDA, Laiz. Região metropolitana de Chapecó: dinâmicas regionais e suas territorialidades. In: PEREIRA, Denise; CARNEIRO, Maristela (Orgs). Investigação científica nas ciências sociais aplicadas. v.3. Ponta Grossa/PR: Atena Editora, 2019b.

MAIA, Claudio Machado; PITSCHEL, Gabriel. Análise regional de Chapecó e de 5 cidades de influência. In: XXIII Congresso Brasileiro de Economia. Florianópolis/SC: CentroSul, 2019a.

MAIA, Claudio Machado; PITSCHEL, Gabriel. Análise regional de Chapecó e de 5 cidades de influência. Colóquio - Revista do Desenvolvimento Regional. Taquara/RS. v.16. n. 3. jul./dez. 2019b.

MAIA, Claudio Machado. Abordagens não dicotômicas do desenvolvimento: ação a distância, tecnologia informacional e o posicionamento estratégico de atores. In: OLIVEIRA, Odete Maria de (Org). Relações internacionais, direito e poder: atores não estatais na era da rede global. v.3. Ijuí/RS: Ed. Unijuí, 2016.

MAIA, Claudio Machado. Um ensaio sobre a noção de território nas pesquisas sobre desenvolvimento rural e regional In: Território e Sociedade: perspectivas teóricometodológicas e evidências empíricas.1 ed. Porto Alegre: Tomo Editorial Ltda, 2014.

MAIA, Claudio Machado; ROLIM, Aparício. O processo de metropolização e condições de urbanização: novas territorialidades e novas dinâmicas espaciais em cidades de maior influência no oeste catarinense. In: PIOVEZANA, Leonel; CECCHETTI, Elcio; OLIARI, Gilberto Oliari; OLDIGES, Monica Maria Tourinho (Orgs). Anais. II Seminário Internacional de Culturas e Desenvolvimento (SICDES), II Congresso Sul-Brasileiro de Promoção dos Direitos Indígenas (CONSUDI) e V Colóquio Catarinense de Ensino Religioso. Chapecó: Argos, 2015.

MAIA, Claudio Machado; SANTIN, Myriam Aldana Vargas; ALBA, Rosa Salete; VILLELA, Ana Laura Vianna. Metropolização e Condições de Urbanização: Novas Territorialidades e Novas Dinâmicas Espaciais em Cidades de Maior Influência no Oeste Catarinense In: $2^{\circ}$ Seminário de Desenvolvimento Regional, Estado e Sociedade (SEDRES). A Diversidade Regional Brasileira em Perspectiva, Anais GT6. Campina Grande/PB: EDUEPB/UEPB, 2014.

MAIA, Claudio Machado; FUJITA, Camila; ALBA, Rosa Salete. Reestruturação produtiva e dinâmica urbana e regional no oeste catarinense: uma análise do papel de Chapecó e outras cinco cidades influentes In: XV Encontro da Associação Nacional Planejamento Urbano e Regional. Recife/PR: XV ENANPUR, 2013.

MAIA, Claudio Machado; LUDWIG, Dione Paula. Novas territorialidades regionais no oeste catarinense: reestruturação produtiva e urbana das cidades de maior influência da região. In: 1o Seminário Nacional de Planejamento e Desenvolvimento. Curitiba/PR, 2013?

MAIA, Claudio Machado, RIEDL, Mario, SCHUSTER, Celso. Análise regional do COREDE Nordeste. Perspectiva Econômica (Online). v.4. p.65/2 - 85. São Leopoldo/RS, 2008. 
Atlas Socioeconômico do Rio Grande do Sul. Secretaria de Planejamento, Orçamento e Gestão (SEPLAG). Porto Alegre: SEPLAG, 2018.

MONASTERIO, Leonardo. Indicadores de análise regional e espacial. In: CRUZ, Bruno de Oliveira; FURTADO, Bernardo Alves; MONASTERIO, Leonardo; JÚNIOR, Waldery Rodrigues. Economia regional e urbana: teorias e métodos com ênfase no Brasil. IPEA: Brasília, 2011.

NORTH, Douglas C. Instituições, mudança institucional e desempenho econômico. Tradução de Alexandre Morales. Título original: Institutions, Institutional Change and Economic Performance. São Paulo: Três Estrelas, 2018.

NORTH, Douglass C. Economic performance through time. American Economic Review, 1994. v.84, n.03. p.359-368.

NORTH, Douglass C. Institutions. Journal of Economic Perspectives, 1991. v.05, n.1, p. 97-112.

NORTH, Douglas C. Location theory and regional economic growth. Journal of Political Economy, Chicago, III.US: University of Chicago Press, n. 43, p. 291, jun. 1955.

NORTH, Douglas C. Agriculture in regional economic growth. Journal of Farm Economics, Lancaster, Pa., US: American Farm Economic Associoation, v. 4, n. 5, p. 333, dec. 1959.

PAIVA, Carlos Águedo. Fundamentos da análise do planejamento de economias regionais. Foz do Iguaçu: Editora Parque Itaipu, 2013.

PAIVA, Carlos Águedo Nagel. Desenvolvimento Endógeno e Potencialidades Regionais. Porto Alegre: FEE, 2006a. 21 p. [mimeo].

PAIVA, Carlos Águedo Nagel. Desenvolvimento Regional, Especialização e suas Medidas. In: Indicadores Econômicos. v.16. n.2. Porto Alegre: FEE, 2006b.

PAIVA, Carlos Aguedo Nagel. Re-regionalizar o RS para planejar o desenvolvimento endógeno dos territórios retardatários: um programa de pesquisa em curso. Porto Alegre: FEE, 2006c. 13 p. [mimeo].

PAIVA, Carlos Aguedo Nagel. Regionalização com vistas ao planejamento do desenvolvimento endógeno sustentável. In: Primeiras Jornadas de Economia Comparada, 1, Porto Alegre 2005. Anais... Porto Alegre, FEE/PUCRS, 2005.

PAIVA, Carlos Águedo Nagel. Como identificar e mobilizar o potencial de desenvolvimento endógeno de uma região? In: Documentos FEE. n .59. Porto Alegre: FEE, 2004.

PIACENTI, Carlos Alberto; LIMA, Jandir Ferrera de; EBERHARDT, Paulo Henrique de Cezaro (Orgs). Economia e desenvolvimento regional. Editora Parque Itaipu: Foz do Iguaçu, 2016.

PINTO, Hugo Eduardo Meza; MEZA, Maria Luiza Figueiredo Gomes de. Reflexões sobre o desenvolvimento regional em regiões subdesenvolvidas. In: CATAPAN, Anderson;

COMERLATTO, Dunia; OLIVEIRA, Francisco Henrique de. Políticas Públicas e Desenvolvimento: tendências contemporâneas. Editora CRV: Curitiba/PR, 2020.

SOUZA, Marcelo Lopes de. O território: sobre espaço e poder, autonomia e desenvolvimento. In: CASTRO, Iná Elias de; GOMES, Cesar da Costa; CORREA, Roberto Lobato. Geografia: conceitos e temas. 20 ed. Rio de Janeiro: Bertrand Brasil, 2000. p.77-116.

VIEIRA, P. F.; CAZELLA, A. A. Desenvolvimento territorial sustentável em zonas rurais: subsídios para a elaboração de um modelo de análise. In: Seminário Internacional Territórios Rurales em Movimiento: Movimientos Sociales, Actores e Instituciones Del Desarrollo Territorial Rural. 
Santiago de Chile, 2006. Disponível em: <http://www.rimisp.org/seminariotrm/doc/ANTONIOCAZELLA.pdf>. Acesso em 27 de julho de 2020.

VILLELA, Ana Laura Vianna; ALBA, Rosa Salete; MAIA, Claudio Machado; ARRUDA, Laiz. Região Metropolitana de Chapecó: dinâmicas regionais e suas terrirorialidades In: II Encontro Nacional de tecnologia Urbana (ENURB). Anais II Encontro Nacional de tecnologia Urbana. Passo Fundo/RS: UPF Editora, 2015. 